\title{
Communication
}

\section{Science for Good Environmental Status: A European Joint Action to Support Marine Policy}

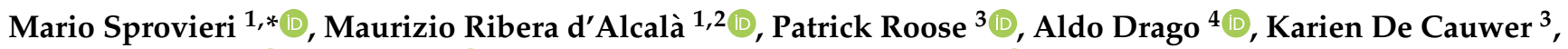 \\ Federico Falcini ${ }^{5}{ }^{\oplus}$, Inga Lips ${ }^{6}\left(\right.$, , Chiara Maggi ${ }^{7}$, Aourell Mauffret ${ }^{8}{ }^{\circ}$, Jacek Tronczynski ${ }^{8}$, Christina Zeri ${ }^{9}$ \\ and Pier Francesco Moretti ${ }^{10,11}$
}

check for updates

Citation: Sprovieri, M.; Ribera d'Alcalà, M.; Roose, P.; Drago, A.; De Cauwer, K.; Falcini, F.; Lips, I.; Maggi, C.; Mauffret, A.; Tronczynski, J.; et al. Science for Good Environmental Status: A European Joint Action to Support Marine Policy. Sustainability 2021, 13, 8664. https://doi.org/ $10.3390 /$ su13158664

Academic Editor: Tim Gray

Received: 21 June 2021

Accepted: 25 July 2021

Published: 3 August 2021

Publisher's Note: MDPI stays neutral with regard to jurisdictional claims in published maps and institutional affiliations.

Copyright: (c) 2021 by the authors. Licensee MDPI, Basel, Switzerland. This article is an open access article distributed under the terms and conditions of the Creative Commons Attribution (CC BY) license (https:// creativecommons.org/licenses/by/ $4.0 /)$.
1 Istituto per lo Studio degli Impatti Antropici e Sostenibilità in Ambiente Marino (IAS-CNR), Torretta Granitola, 91021 Trapani, Italy

2 Stazione Zoologica Anton Dohrn, 80121 Napoli, Italy; maurizio@szn.it

3 Royal Belgian Institute for Natural Sciences, Vautierstraat 29, 1000 Brussels, Belgium; proose@naturalsciences.be (P.R.); kdecauwer@naturalsciences.be (K.D.C.)

4 Department of Geosciences, University of Malta, MSD 2080 Msida, Malta; aldo.drago@um.edu.mt

5 Istituto di Scienze Marine (ISMAR-CNR), Via Fosso del Cavaliere 100, 00133 Roma, Italy; federico.falcini@cnr.it

6 European Global Ocean Observing System, EuroGOOS AISBL, Rue Vautier 29, 1000 Brussels, Belgium; inga.lips@eurogoos.eu

7 Istituto Superiore per la Protezione e la Ricerca Ambientale (ISPRA), 00144 Roma, Italy; chiara.maggi@isprambiente.it

8 Ifremer, Unit of Biogeochemistry and Ecotoxicology, 44311 Nantes, France; Aourell.Mauffret@ifremer.fr (A.M.); Jacek.Tronczynski@ifremer.fr (J.T.)

9 Institute of Oceanography, Hellenic Centre for Marine Research (HCMR), 19013 Anavyssos, Greece; chris@hcmr.gr

10 JPI Oceans/National Research Council of Italy (CNR-UREI), Rue de Trone 4, 1000 Bruxelles, Belgium; pierfrancesco.moretti@cnr.it

11 National Research Council of Italy, P.le A. Moro 7, 00185 Rome, Italy

* Correspondence: mario.sprovieri@cnr.it

Abstract: In the last decade, several initiatives have been taken at a European level to adopt the Marine Strategy Framework Directive (MSFD) by promoting coordination and stimulating integrated actions leading to consistent views on its final goal: the achievement of good environmental status (GES). In its holistic approach, the MSFD fully acknowledges the complexity and variability of marine ecosystems and demands constant scientific support for its actual implementation. Recently, the Joint Programming Initiative on "Healthy and Productive Seas and Oceans" (JPI Oceans) launched the joint action "Science for Good Environmental Status" (Science4GES), building on the contribution of different scientific disciplines and communities to better fulfill the scope of the MSFD. In this paper we illustrate and discuss a few crucial aspects of endeavors to implement the MSFD specifically implied in the definition of the metrics for the 11 descriptors and GES in its complexity, as well as improving the strategy governing its implementation. This presentation also describes the challenges, aims and implementation plan for the JPI-O joint action, where a transdisciplinary approach may help in progressing from the comprehensive and far-reaching vision of the MSFD to the achievement of a durable GES.

Keywords: Marine Strategy Framework Directive; S4GES JPIO action; Good Environmental Status; science-based support for MSFD

\section{Introduction}

The European Integrated Maritime Policy [1] aims to achieve coherence across the range of economic activities in the marine environment carried out by different marine sectors. The uses of marine resources should be constrained within sustainable limits, as stated by the 'Blue Growth Directive' [2] and need to be harmonized as outlined by 
the Maritime Spatial Planning Directive (MSPD, [3]). In this context, the Marine Strategy Framework Directive (MSFD, [4]) sets the standards conducive to sustainable marine ecosystems, and provides the overarching compliance criteria that need to be followed in conducting such economic activities (e.g., [5]).

The MSFD promotes actions for environmental assessments, defines environmental targets and sets programs of monitoring and measures, with the overall objective of maintaining or restoring the good environmental status (GES) of European seas and their resources.

Our limited knowledge of the functioning of marine ecosystems is a stumbling block in securing the long-term sustainable exploitation of seas and the maintenance of marine ecosystem services over the coming decades (e.g., [6,7]). The MSFD is one of the initiatives taken so far to establish criteria for the exploitation of the sea with a precautionary approach, in order to prevent irreversible changes and to possibly revert or mitigate changes already caused by human activities in the marine realms.

The innovations in environmental policy progress, as proposed by the MSFD, should reside now in fostering an integrative, holistic ecosystem approach, looking at marine environments as ensembles of functional units with complex interactions fully coupled with the socio-economic system. This view constitutes the holistic ecosystem approach, which is the novel trait of the MSFD (e.g., [8]). However, even considering the marine environments by themselves, the very many organisms that interact with one another and with their abiotic contexts form a complex system, whose non-linear dynamics are hard to assess. Since the survival of one organism depends not only on abiotic (nutrients, temperature, resources, pollutants, hydrodynamic forcing, etc.) and biotic (metabolic capacity, range of tolerance to variations, plasticity, etc.) constraints, but also on its interactions with other organisms, the pressure on one species cannot be understood only in terms of univariate, prevalently abiotic-biotic interactions. Likewise, because of these multiple interactions the local extinction or migration of one species may impact the whole community (e.g., [9]), which thus demands us to go beyond the census of target species [10].

The backbone of the MSFD is a set of 11 descriptors which explicitly address key traits or processes linked to marine ecosystems, like the perturbations induced by anthropogenic pressures (descriptors 2, 3, 5-8, 10 and 11), and the persistence of the intrinsic structure (descriptor 1) or functioning (descriptor 4) of the systems [11]. The descriptors are formulated to describe how the processes should go, though very qualitatively, to secure the good status of such systems. On this basis, the MSFD proposes a list of indicators (characteristics, pressures and impacts in Annex III in MSFD) which, once determined, should lead to an assessment of the status of the environment (the descriptors) and subsequently to the overall qualification of the environmental status. Despite the innovative ecosystem view providing the conceptual framework of the 11 key descriptors and the connected 57 criteria [2], the implementation of the MSFD faced several difficulties, among which were discrepancies among the regions in the procedures for the assessment (e.g., [12-15]), difficulty in moving beyond semi-quantitative assessments often based on expert knowledge (e.g., [16]), ambiguity in the use of terms (e.g., [11]) and geopolitical and governance problems [17-21]. Therefore, a number of initiatives have recently been promoted to improve the implementation of MSFD to comply with its integrative view in favor of a sustainable use of the sea (e.g., [22,23]). Among these, specific efforts have explored aspects related to the metrics for the estimation of the various indicators, and the criteria (and possibly values of the observables associated to the criteria) needed for the assessment of GES (e.g., [24] for D4). The MSFD came into force in 2008 with the goal of achieving GES by 2020. This interval represents the timeframe of the directive and encompasses the necessary time for its implementation at national levels. In 2018, the directive entered its second cycle (art. 17, [4]) when countries are required to achieve coherent, coordinated and consistent updates of the determinations of GES. The initial assessment of, and the member states reports on, the environmental status carried out in the first six-year period showed a large variety of capacities and approaches, mainly 
describing a range of complexities and difficulties in the implementation of the directive from several points of view (e.g., [25]). Challenges seem to be associated with the basic assumptions, i.e., the definition and the metrics connected to the assessment of GES as clearly revisited and refined in the second commission decision [2]. Moreover, the first commission's assessment [26] showed the need for significant improvements in the quality, coherence and consistency of the definition of GES by member states.

The European Commission recognized that the criteria, methodological standards, and specifications for GES monitoring and assessment should be based on the best available science and technology, as well as on their improvements and progress when needed [2]. Despite this growing awareness, a more comprehensive and coherent connection between science and MSFD still needs to be effected to make practical and operational aspects efficient in providing effective assessments. In particular, we believe that (i) effective linkages between emerging knowledge, innovative approaches and techniques in marine science, and their implementations within the MSFD context should be developed; (ii) criteria, including threshold values, methodological standards and proper representation of the MSFD descriptors, improved on the basis of scientific and technical progress, should be periodically reviewed and amended; (iii) efficient mechanisms to develop and include new and innovative observational schemes and techniques, available for the member states, should also be built and strengthened (e.g., [27]). These efforts should lead to more consistency in the determination of the GES of different marine regions in the European seas.

Science must contribute to a revision of criteria, including the introduction of new criteria; develop sound risk-based approaches where needed; provide rigorous definitions and sharpen and refine or specify the concept of thresholds and subsequently of GES. Science also has a responsibility to foster data harmonization and interoperability, as well as to seek integrations among MSFD descriptors.

MSFD has made a valuable contribution to enhancing the awareness of the need for the protection of the marine environment within the scientific community, as testified by the more than 800 papers discussing the MSFD since 2002 (source: https:/ / clarivate. $\mathrm{com} /$ webofsciencegroup/solutions/web-of-science/). However, this does not immediately translate into social awareness, which is still partial and often disconnected from institutional initiatives such as the MSFD [28]. Today, after more than ten years of driven initiatives, it is timely to provide a refreshed perspective with a robust and mature approach to the definition of GES and its complexity. Indeed, the assessment metrics for the various environmental aspects covered by the 11 descriptors are critical. In particular, defining more clearly what we mean with the term "good" in environmental status evaluation is necessary, as only this can lead to an appropriate, practical approach and the successful implementation of the directive.

Herein, we report on the challenges, aims, implementation plan and progress of a European action launched by the Joint Programming Initiative on Healthy and Productive Seas and Oceans (JPI Oceans) in November 2019 named Science for Good Environmental Status (Science4GES; https: / / www.jpi-oceans.eu/interdisciplinary-research-goodenvironmental-status), which was intended to pave a complementary path to structure the science-policy interface to support GES. JPI Oceans is an intergovernmental strategic platform to coordinate and integrate research programs for tackling marine and maritime challenges. It was officially adopted in 2011 by the Council of the European Union and involves research funders from the European member states, associated countries and international partners in different typologies of action (https://jpi-oceans.eu/). The joint action Science4GES, within JPI, aims to contribute to a better understanding of GES and achieving it in a more integrative way, i.e., by expanding the ecosystem view up to governance, thus supporting the implementation of the MSFD and ultimately the sustainable use of the sea (https:/ / www.jpi-oceans.eu/interdisciplinary-research-good-environmental-status). Key to this will be improving our understanding of marine ecosystem functioning, how multiple activities impact the environment, how to fulfil the requests of MSFD (see 
https:/ /www.jpi-oceans.eu/interdisciplinary-research-good-environmental-status) and how to govern the whole process.

\section{Materials and Methods}

As anticipated in the Introduction, this contribution is not an experimental study but is a reflection on the synthesis of a discussion carried on during the preparation of the JPI-Oceans action. Therefore, it is not based on experiments or novel observations in the environment. Rather, it is based on a careful reading of the main EU documents on the MSFD which is part of the truly vast literature published so far on the problems, methods and practices related to the MSFD. The documents and the studies which were relevant for illustrating the view of the authors are all included in the References section. They constitute the materials. The method, as already mentioned, has been the exchange of ideas taking place mostly in two workshops organized to set up the JP-Oceans action. Our motivation for proposing publication in Sustainability is twofold. Firstly, Sustainability constitutes an "advanced forum for studies related to sustainability and sustainable development" and the MSFD has been the first attempt at a European level to foster a holistic ecosystem approach to make the use of the ocean more sustainable. Secondly, since its formulation, most of the attention of the scientific community has been focused on the validation, refinements and homogenization of observational methods, i.e., on the application of MSFD, while, in the view of the authors, some key components of the MSFD demand a better framing in modern scientific theories, which might improve the operational approaches to foster sustainability.

\section{Results}

\subsection{Good Environmental Status}

The determination of GES is based on fulfilling the criteria, as implicitly established by the statements summarized by the 11 descriptors of MSFD ([4], Annex I), that describe the key traits or processes of the systems that should be primarily considered. Their assessment should be based on the values of ocean variables, associated with different ecosystem features, and human pressures and their impacts on them. These variables (human pressures and their impacts), most of which are state variables, and their related indicators should be relatively simple to measure and communicate, allowing a better common understanding across disciplines and better information transfer, giving policy makers a clearer picture of changes and trends in the ocean system.

In subsequent documents, e.g., the commission decision 2017/848 of 17 May 2017, all of the above was better clarified. The 'Qualitative Descriptors' of Annex I of the MSFD, which were indeed very general criteria, as well as the features and pressure to consider for assessment, were better explained and translated in the 'Criteria Elements.' These, in turn, should have also included appropriate indicators, methodologies and thresholds on the basis of which the assessment of the status and the achievement of the targets for GES could be accomplished. In brief, assessment of GES should have been based on the identification of thresholds for specific indicators, monitored with established methodologies and related to the features and pressures on marine environments. Thresholds are static values of state variables while ecosystems vary in space and time.

The resolution of temporal and spatial variability, as well as of environmental feedback, in the marine realm remains particularly difficult, because of its intrinsic complexity and the non-linear dynamics (e.g., [29]) and internal connectivity that strongly characterize these ecosystems [30-33]. This also implies that the determination of statistically robust trends requires long-term time-series datasets, whereas indicators may also show different and delayed responses to anthropogenic pressures and changes in environmental hydrological, climatic and ecological conditions (e.g., [34]).

The analysis and identification of threshold values through EU and regional cooperation (particularly the most recent DG-ENV-supported projects MEDCIS and MEDREGION for the various descriptors, and the past research on thresholds of the DG-ENV activities 
ActionMed, IRIS-SES and H2020 DEVOTES), represent a scientifically challenging task (e.g., $[5,35])$. Threshold identification assumes a sufficient knowledge of the dynamics of the system to allow us to anticipate a shift in its functioning, should the threshold be exceeded. Knowledge of (i) regime shifts and tipping points in ecosystem responses, and (ii) the physical, biological and biogeochemical dynamics of the system, are therefore key in the identification of relevant threshold values.

The achievement of a long-lasting GES might be better warranted by considering these ecosystems as dynamical entities, better characterized by trajectories than by the fixed values of observables $[16,36]$. Furthermore, besides profiting from the continuous growth of new observational and numerical tools (e.g., [27-29]), the implementation of the MSFD would also benefit from an integrated approach to data analysis.

An improved MSFD approach should, therefore, take into account a clever exploitation of additional tools, such as the advanced use of computational methods to map and model environmental changes and impacts (e.g., statistical or mechanistic ecological models); their coupling with observational data, also via data assimilation; their interoperability via open standards and the exploration and exploitation of new technologies, sensors and additional variables (e.g., [37-39]) which may fill existing gaps in understanding key processes in marine ecosystems. In summary, the MSFD sets sound, broad 'criteria' as the basis for the evaluation of environmental status. However, as a common methodological approach was not proposed by the EU to the member states, metrics were not provided and protocols were not constrained, and so the implications of dealing with geographically distinct, dynamically different, complexly behaving marine ecosystems remain unsettled (e.g., $[12,26,40,41])$.

\subsection{How to Achieve Science-Based Support for the Implementation of MSFD?}

In order to fulfil MSFD requirements, along with the science-policy interface and the ecosystem approach, scientific syntheses of key ecosystem datasets need to be improved for a better understanding of the determination of GES in the European seas. However, despite the wealth of scientific information produced across Europe, much of this knowledge is currently not in a form that can be readily used by policy makers and many stakeholders. We believe that a bigger effort could be made by the scientific community to screen and synthesize acquired knowledge with a focus specifically on providing the needed inputs to comply with MSFD criteria and requirements. This sets a first target (rescue and revisit the accumulated information and knowledge to exploit it from an MSFD perspective) like the one carried out in the International Panel on Climate Change [42] or the Millennium Ecosystem Assessment [43] communities. Furthermore, revealing trends and learning the impacts of pressure, including cumulative impact assessments on the marine environment, call for systematic observations over time. Understanding and integrating environmental information with societal and economic developments and goals is also more and more essential for an effective policy on the sustainable use of marine and maritime resource. The gap existing between the earth system science community and the socio-economic community (e.g., [44]) is a serious obstacle, because no GES achievement will be ever possible without designing alternatives for socio-economic drivers.

The support of science for policy and governance should thus involve efficient and effective science-based information and tools, ensuring that the resilience of marine ecosystems to human-induced changes is not compromised. In this context, science can and should support decisions and interventions, which in turn involve actors and components far from the competences of the marine community. One of the problems recently highlighted is that the programs of measures carried out by different countries rely mostly on previous policies and do not derive from a homogeneous, consistent plan based on the possible new insights derived from MSFD-specific activities [21].

We believe that what is on the agenda of the marine science community is to quantify the key processes that contribute to the variability and stability of the marine environment. Building on this, it should be possible to (i) set proper observing systems in the light 
of the fact that we are likely still not measuring what actually counts but, often, merely whatever we can actually measure [45] and (ii) set hypotheses and formulate effective equations based on evidence, and subsequently collect ad hoc data. Blending observing systems, modelling and theoretical studies will entail a synergetic approach towards the definition of new methodologies and a recognition of the essential number of observables and/or indicators.

\subsection{Data Compilation in Standardized and Public Datasets}

Ocean data, at national and EU level, appear sparse and heterogeneous in terms of targeted variables, quality, sampling methodologies and strategy, etc. (e.g., [11,23,41,46-48]. This implies difficulties in providing available, harmonized data sets for interoperability, comparability and for calibration and validation activities. Indeed, a harmonized strategy is often lacking, due to what is available and/or feasible, based on national capacities. These considerations were at the base of the EMODnet Sea Basin Checkpoints (https: / /www. emodnet.eu/checkpoints), which assessed the quality of observation monitoring data at the level of regional sea-basins by testing the data against specific end-user challenges. The checkpoint data gaps and duplications as well as significant bottlenecks will be highlighted with the contribution of S4GES's effort. The harmonization strategy we propose for MSFD implementation will take advantage of and get feedback from EMODnet organizations in recognizing and filling emerging gaps in marine data availability.

Moreover, a holistic investigation of the marine ecosystem cannot be approached by addressing the status of the system as the sum of single parts. In complex systems, such as the marine environment, the "estimate" obtained as the sum of the single components does not correspond to the one for the whole system and thus, the scientific community is compelled to look for emerging properties [49].

In such a context, data alone will never be enough to fully represent and predict the spatial/temporal variability of the system. A categorization and process-based context of data collection is therefore needed, in terms of fitness for purpose, protocols and quality control, in the light of a synergetic use of data along with modelling and remote-sensing analyses. Although there are already good practices in the management of different datasets, it would be beneficial for the scientific community and the end users to have a synthetic overview of the available in situ products that are useful for MSFD descriptors. These products should also support the model outputs and satellite algorithms, which can provide a large-scale, synoptic picture of the physical and biogeochemical context. By enhancing this synergy, MSFD descriptors can be closely linked to their scientific meaning. The integration of earth observations (EO), remote and in situ, with modelling is conducive to achieving the goal of defining "trajectories" in time of state variables, thus analyzing the ecosystem as a whole in both space and time. Data collection, together with the intercalibration of data and data management, should focus on the dynamics of the ecosystem, within the context of an integrated observing system.

The Science4GES initiative aims at fostering all the above.

\subsection{The Implementation Plan of Science4GES}

\subsubsection{A Workshop Series as an Exchange Opportunity for the MSFD}

The S4GES project is planning a series of scientific MSFD European workshops for sharing new knowledge and its practical understanding, conceptual approaches and the identification of needs and clues, as a structured learning process that will support an "official task group", the Marine Strategy Competence Center, and, in general, the entire community working and addressing the MSFD. These workshops intend to induce a bottomup energetic flow in the scientific community, where researchers from different disciplines will be cross-fertilized, thus paving the way to a realized holistic approach. This will be further boosted by training schools for the younger generations. This activity will also set possible platforms (e.g., an EU policy lab, knowledge hub and blue-bridge virtual research environments) and adapt the implementation of the MSFD to different needs, 
for a better determination of GES. Among others, successful examples of the direction described above have been represented by the two EU projects DEVOTES [50] and STAGES, and the creation of the MSFD European Competence Center, which should provide a comprehensive repository of scientific information on the MSFD.

The proposed approach will also contribute to structuring a dialogue between different experts and facilitate a transformation from a silos approach (still disciplinary) to a true ecosystem approach, aiming at building rules of correspondence between different communities.

The process of circulation of knowledge and ideas, open to contributions from different scientific communities and experiences, will result in background and reflection documents about gaps and needs that are behind those questions set by policy makers. This documentation will support decision makers to proceed in launching joint actions or revisions when implementing the MSFD.

The MSFD European workshops organized under the S4GES action will also represent the "knowledge environment" where priorities and specific activities focused on approaches to joint integrated observations (described in the following two paragraphs) will be identified and set up, creating a scientific 'fil rouge' and comprehensive conceptual support for the JPI-O action.

\subsubsection{Joint Integrated Observations}

The development of integrated observing systems should include shared trans-disciplinary monitoring platforms. Such a novel system can be achieved if specific activities are dedicated to the design of integrated methodologies and the development of technologies for monitoring the relationships and actions of biological and morphological features, omics, behavioral traits, etc., and biogeochemical and physical processes. This would help to assist member state groups to implement monitoring programs according to adopted strategies, and to promote common systems, by transferring knowledge and methods, in practice, through direct hands-on joint actions at the national level. Moreover, the proposed integrated observations will finally bring about harmonized, region-wide, innovative, costefficient and effective schemes for the assessment of GES, for instance from the synergy of modelling, satellite and in situ products.

It is necessary to take into account the analysis of essential variables, sampling techniques and strategies, methodologies, calibration activities, data management and reporting, the reduction of costs and identification of central funding. In particular, testing the interoperability of data (for a number of case studies), in order to integrate information towards meaningful results, will identity feasible, efficient and effective implementation approaches at a national level. Specific wrap-up indicators, able to account for a large variety of single parameters, and common protocols will be selected and used as benchmarks for future interventions. In this context, the mounting of integrated, joint monitoring actions, organized, for instance, on shared multi-party and cross-disciplinary teams on board European research vessels, will be also evaluated. The increased capacity building and presence of multi-disciplinary experts on board observing campaigns will act as bridges to operators and responsible authorities in an interconnected MSFD network.

These innovative joint surveys are therefore envisioned as a downstream activity that results from the synergetic analysis of model (physical and biogeochemical) outputs, remote sensing products and available in situ measurements, in order to test hypotheses and collect crucial data that may emerge from gap analyses. Finally, to meet evolving ocean observation needs for MSFD, the role of joint, integrated observation approaches as a part of the European Ocean Observing System (EOOS) will be taken into account in national implementation. In this context, the integration of the European research oceanographic fleet for conducting periodic MSFD-oriented surveys may create an appropriate framework for better collaboration and interoperability of member states within emerging areas of activity, sharing methodological advancements and coherent approaches.

The Copernicus Marine Service (CMEMS), i.e., one of the seven services of the European Copernicus program, responds to issues emerging in the marine environmental- 
scientific sectors. By using satellite and in situ observations, it provides state-of-the-art analyses and forecasts that offer the opportunity to observe marine environment events. The integrated system proposed by S4GES will take advantage of continuous feedback with the marine Copernicus community, in particular, by comparing approaches and methodologies with those implemented in the CMEMS Ocean Monitoring Indicators (OMIs), i.e., the available trends and data sets covering the past quarter of a century of key variables used to track the vital signs of the ocean and changes in line with climate change.

\subsubsection{Approaches of Augmented Observatories}

The augmented observatories should be conceived of as integrated monitoring and experimentation infrastructures (Figure 1) The definition of augmented observatory used here is that adopted by the G7 working group (http:/ / www.g8.utoronto.ca/science/20 17-annex1-seas-oceans.html), which states that "A deeper understanding of our oceans and seas is needed for a better understanding and prediction of natural phenomena and the impact of human activities on ocean ecosystems, their resilience and effect on climate, including how and why the oceans are changing. This requires the continuation of existing observations that are augmented by new technologies in an integrated, coordinated and consistent way that also helps to close existing gaps" (see also [46]). Key to success will be the synopticity and co-localization of observations relying on autonomous buoy stations or, for specific regions, on ships-of-opportunity, floats and gliders. The use and integration of innovative techniques will enable the provision of data with an appropriate resolution in time and space for the assessment of the status, progress towards environmental targets and effectiveness of measures to achieve GES. Sampling will also be needed, and a multiplatform adaptive sampling strategy should be developed. This can be accomplished by experimenting with changing sampling rates and/or sampling scales or by integrating autonomous mobile platforms such as gliders and AUVs, based on their outputs. Such observatories would generate massive amounts of data covering multiple variables and hence could, through multi-use, satisfy the needs of many interested stakeholders-scientists, politicians and environmental and operational agencies. These observations would need to be linked to hydrodynamical models, not only to allow model testing and correction, but also in relation to understanding environmental processes. These new approaches, together with a harmonized view of specific and crucial indicators, will provide an unprecedented opportunity for understanding the marine ecosystem. The ultimate goal is to provide science-based novel approaches allowing the implementation of the MSFD and describing more adequately the marine ecosystem and changes therein.

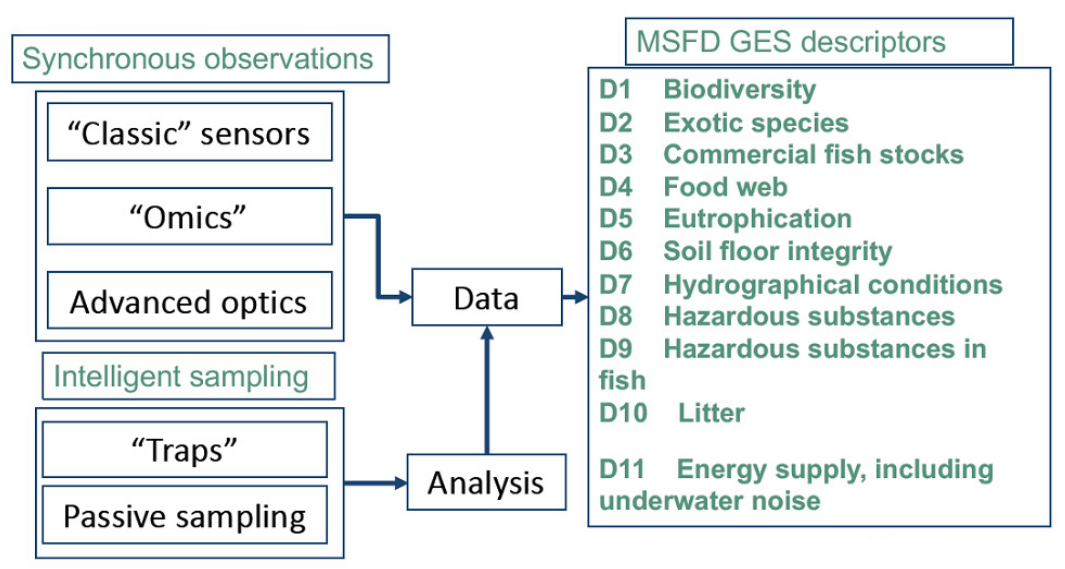

Figure 1. Conceptual flow from integrated observations, analysis and data management for assessment of MSFD descriptors. 


\section{Implementation and Governance of the Action Science4GES}

Assessing the status of the seas and oceans is a challenge that involves complexity in terms of the interconnection of the physical, chemical and biological variables acting to constitute the marine ecosystem as a whole. Merely defining the "health" of the marine environment opens a Pandora's box with respect to meaning and approach.

Seas and oceans are a challenging environment to manage per se. Among these challenges, there is the problem of having to deal with dynamic or absent boundaries and variable scales, which are defined by issue, e.g., pollution and fisheries, that contrast with the existence of the rigid, jurisdictional boundaries that set the responsibilities for the intervention.

On one hand there is the need for monitoring the dynamics, understanding the drivers and effects of human and natural inputs in the marine system, as well as evaluating effective interventions to maintain or restore its health, which are grounded at the level of marine science. On the other hand, the interrelations of socio-economic, environmental-legislative and geo-political aspects require a different level of knowledge and actions which often do not dialogue with the former level, because they involve a diversity of stakeholders, sectors and disciplines which are outside marine science sensu stricto.

While JPIO S4GES, at first sight, seems to address the scientific challenges of understanding the marine ecosystem "solely," in fact it aims at making effective and efficient activities for achieving a "good" status, and designing and implementing the action needs, therefore, a comprehensive and integrated approach.

Any implementation of an action refers to what is usually named "governance," which comprises the ensemble of process and actors which support the activities aimed at achieving the objectives.

Concepts, structures, modes, schemes and properties of governance crowd the literature, and the ambiguity of these notions may have contributed to its abundant popularity but abused use. In particular, ocean governance is usually oversimplified, because is based on a linearized representation of the system: the natural environment on one side, and the institutional structures which have interests or responsibilities in governing seas and oceans on the other side. Indeed, governance relates to the processes of interaction and decision-making among the actors involved in a 'collective' problem, which ultimately lead to the creation, reinforcement or reproduction of social forms or structures including institutional and informal boards.

In recent years, political scientists have largely debated about "governance" and new modes of governance [51-54]. They associate the concept with a wide variety of different phenomena, from decision-making processes to the development of policy instruments, thereby addressing different institutional structures and actor constellations.

The term governance has therefore evolved as a generic fundamental concept which comprises all institutionalized forms of political steering and the integration of societies, into an intricate combination of sociological-economic theories and organizational models.

The numerous theoretical models and diversity of applications and contexts have likely strongly discouraged the identification of a feasible and effective design for the governance of a complex system [55-58]. This approach to MSFD mainly adopts a mode of governance which could be similar to "network governance." In the European Union, this is assumed to be dominant with respect to "statism," "pluralism" and "corporatism" [59], and the relationship between public and private actors in the process of policymaking is its main aspect. In the case of MSFD, the private sector is largely missing, but the network mainly include different agents within member states and the commission, with the involvement of responsible authorities and stakeholders as well. Nonetheless, it is a mostly a top-down process. The governance of MSFD at the moment does not show any attempt to approach the complexity of the constellation of actors, roles and interests. Indeed, it shows a very crystallized institutional network, with a considerable time of response and resistance to change. Despite the enormous budgets invested by member states and the European Commission (EC) in the monitoring system and the analysis of 
the data, information is often incomplete or not adequate to make advances on the path towards the goals. The governance of the process is indeed fundamental to enabling the combination of dimensions and levels (roles, stakeholders, funds and data) to provide effective and efficient products. In this context, private companies have developed new topologies for their own connectivity, and we are definitely facing the unstoppable power of leaderless organizations [60].

We are fully convinced that, in order to manage, steer and coordinate the interdependent actors framing the complex challenge of the GES, it is crucial to be aware that no aspect is dominant or ruling. The engagement of multiple stakeholders has often been promoted and models to manage the environmental challenges proposed [17,61], but an efficient process to match human activities and environmental protection is still a long way from being effectively implemented.

Environmental governance asks for an optimal fit-to-purpose structuring arising from a self-organization process, which embeds top-down and bottom-up processes.

To simplify the complexity of the governance problem, we remark that a lot of science has been already developed in this regard, mainly in the field of the optimization of networks, which could set a reference for the proposition of more effective models of governance in order to allow for GES to be achieved [62,63].

When translating these concepts in the context of the action S4GES and its contribution to the MSFD, it is important to remind oneself that the MSFD is not a unique framework for GES, but an "influence zone" of JPI-O. JPI-O is an intergovernmental European platform to coordinate national research programs on marine and maritime issues. That is, it mainly addresses scientists and public funding organizations for research activities. Presently, many scientists are members of boards which support policy, and their organizations are officially appointed by the responsible authorities as contributors to fulfilling the directive. JPI-O action cannot influence a system where legislation, economic sectors and geographical scales are considerably out of control and poorly permeable to suggestions. Nevertheless, JPI-O can adopt many different typologies of activities, and, with an appropriate design, can induce the system to evolve towards the desired objectives. It is a matter of timescales and strategy.

When designing the three lines of activity for S4GES, i.e., i. discussing and training according to a more integrative vision, from the environment to society and back; ii. organizing joint observational campaigns and iii. making suggestions to optimize, enhance and augment autonomous observation systems, all previous MSFD actions and the present situation became part of the analysis. JPI-O had already contributed to the implementation of other directives, for instance to the Water Framework Directive, promoting a pilot action on intercalibration, where research had been jointly funded by the participating countries and had provided impactful clues for solutions at the policy level. The added value of JPI-O is its role in improving coordination and sharing best practices among the member states. The "Healthy and Productive Seas and Oceans" Joint Programming Initiative is another example of ongoing discussion on the combination of multiple activities on a single platform. JPI-O has also promoted actions, already framed in the context of monitoring and assessment, to foster Good Environmental Status (GES), e.g., "Munitions in the Sea" and "Ecological Aspects of Microplastics."

This being said, S4GES will not compete with actual structured governance but, on the contrary, will hopefully pave a complementary path which will enable a long-term transformation within the processes of assessing the GES. The way the three lines of activities have been selected to facilitate this transformation are based on simple principles:

1 The organization of a workshop series which would induce a bottom-up energetic flow in the scientific community, where researchers from different disciplines would be cross-fertilized and explore new integrative approaches. This would be further boosted by training schools and by reaching out to younger generations.

2 The design of joint observations with increased capacity building and the presence of multi-disciplinary experts on board observing campaigns. 
3 The design of augmented observatories to provide clues and practical demonstration as a heuristic technique to impact the transformation of the approach towards the objective.

Appropriate governance on how to tackle the complexity of the socio-economicenvironmental system has rarely been supported by adequate attention or a knowledgebased approach. It has been mainly associated with the policy dimension and hierarchical organization. Indeed, the governance of complex systems requires appropriate topologies of its networks and the functioning of the interactions between stakeholders. In this regard, we propose reflecting on the different paths and roles of the research community and the responsible authorities, promoting as a first step a cross-disciplinary interaction within the scientific community and a progressive integration of institutional aspects. As well as the change of paradigm in evaluating good environmental status, the governance to achieve it requires a transformation in the structure of the network involved, as well as its dynamics.

\section{Conclusions}

The S4GES action aims at catalyzing an in-depth exchange and discussion on what could retard or hamper the achievement of the farsighted scope of the MSFD. This implies the awareness that not all possible hindrances are evident from the start together with the expectation that S4GES will contribute to highlighting many of them, in particular i. the opportunity for a better exploitation of the existing frameworks for the analysis of multicomponent, strongly interacting dynamic systems, since all marine ecosystems belong to this category; ii. a synthesis of the, so far, quite scattered discussion on the meaning of the indicators and on whether only state variables can properly play such role; iii. a step change in the utilization of pre-existing knowledge which has been the basis for other crucial initiatives, e.g., IPCC (2014); iv. the promotion of interaction among different components of society that are focused, and often rely on, the marine environment, thus not pursuing an integrated eco-socio-economic approach; $v$. an in-depth discussion on what governance is, why it is necessary and in which way it can be implemented to help the achievement of GES. Finally, S4GES, in coping with critical issues related to the deeper and wider knowledge of ecosystem dynamics combined with a balanced exploitation of natural resources preserving the integrity and good functioning of marine ecosystems (in a context of crosscutting environmental issues such as climate change and climate-related hazards), could also represent a pivotal chance for broader international cross-border cooperation and an international consensus on ensuring ecosystem-based approach principles in marine management and maritime domain awareness and security in line with the UN.'s Sustainable Development Goals. As a paradigmatic example, launching the roadmap for developing an integrated marine/maritime policy in the Asia-Pacific region [64] may represent an excellent opportunity for transboundary collaborations integrating global socio-economic and environmental challenges.

Author Contributions: Conceptualization, all; methodology, all; resources, all; writing-original draft preparation, M.S., M.R.d. and P.F.M.; writing-review and editing, all; project administration, M.S.; funding acquisition, M.S. All authors have read and agreed to the published version of the manuscript.

Funding: The two preparatory workshops were funded by the project CISAS (FISR B62F15001070005) supported by the Italian Ministry of Education, University and Research (MIUR) and CNR, in the framework the Special Integrative Fund for Research, while the publication fees for this contribution are provided by the project PON03PE_00203_1 'Marine Hazard' in the framework of the National Operational Programme for Research and Competitiveness (PON) of MIUR.

Institutional Review Board Statement: Not applicable.

Data Availability Statement: All data are publicly available (see list of references).

Conflicts of Interest: The authors declare no conflict of interest. 


\section{References}

1. EC. COM(2007) 575 Final (2007). Communication from the Commission to the European Parliament, the Council, the European Economic and Social Committee and the Committee of the Regions. An Integrated Maritime Policy for the European Union; EC: Brussels, Belgium, 2007.

2. EC. COM(EU) (2017) Commission Decision (EU) 2017/848 of 17 May 2017 laying down criteria and methodological standards on good environmental status of marine waters and specifications and standardised methods for monitoring and assessment, and repealing Decision 2010/477/EU. Off. J. Eur. Communities 2017, 125, 43-74.

3. EU. Directive 2014/89/EU of the European Parliament and of the Council of 23 July 2014 establishing a framework for maritime spatial planning. Off. J. Eur. Union 2014, 257, 135-145.

4. EC. Directive 2008/56/EC of the European Parliament and of the Council establishing a framework for community action in the field of marine environmental policy (Marine Strategy Framework Directive). Off. J. Eur. Union 2008, 164, 19-40.

5. Borja, A.; Elliott, M.; Uyarra, M.C.; Carstensen, J.; Mea, M. Bridging the Gap between Policy and Science in Assessing the Health Status of Marine Ecosystems, 2nd ed.; Frontiers Media: Lausanne, Switzerland, 2017; p. 548. [CrossRef]

6. Carstensen, J. Need for monitoring and maintaining sustainable marine ecosystem services. Front. Mar. Sci. 2014, 1, 33. [CrossRef]

7. Waltham, N.J.; Elliott, M.; Lee, S.Y.; Lovelock, C.; Duarte, C.M.; Buelow, C.; Simenstad, C.; Nagelkerken, I.; Claassens, L.; Wen, C.; et al. UN Decade on Ecosystem Restoration 2021-2030-What Chance for Success in Restoring Coastal Ecosystems? Front. Mar. Sci. 2020, 7. [CrossRef]

8. Levin, P.S.; Fogarty, M.J.; Murawski, S.A.; Fluharty, D. Integrated ecosystem assessments: Developing the scientific basis for ecosystem-based management of the ocean. PLoS Biol. 2009, 7, e1000014. [CrossRef]

9. Guy-Haim, T.; Lyons, D.A.; Kotta, J.; Ojaveer, H.; Queirós, A.M.; Chatzinikolaou, E.; Arvanitidis, C.; Como, S.; Magni, P.; Blight, A.J.; et al. Diverse effects of invasive ecosystem engineers on marine biodiversity and ecosystem functions: A global review and meta-analysis. Glob. Chang. Biol. 2018, 24, 906-924. [CrossRef]

10. Lehtiniemi, M.; Ojaveer, H.; David, M.; Galil, B.S.; Gollasch, S.; McKenzie, C.; Minchin, D.; Occhipinti, A.C.; Olenin, S.; Pederson, J. Dose of truth-Monitoring marine non-indigenous species to serve legislative requirements. Mar. Policy 2015, $54,26-35$. [CrossRef]

11. Berg, T.; Fürhaupter, K.; Teixeira, H.; Uusitalo, L.; Zampoukas, N. The Marine Strategy Framework Directive and the ecosystembased approach-Pitfalls and solutions. Mar. Pollut. Bull. 2015, 96, 18-28. [CrossRef] [PubMed]

12. Palialexis, A.; Tornero, V.; Barbone, E.; Gonzalez, D.; Hanke, G.; Cardoso, A.C.; Hoepffner, N.; Katsanevakis, S.; Somma, F.; Zampoukas, N. In-Depth Assessment of the EU Member States' Submissions for the Marine Strategy Framework Directive under Articles 8, 9 and 10; EU Report EUR 26473; JRC: Ispra, Italy, 2014; p. 151.

13. Veiga, J.M.; Fleet, D.; Kinsey, S.; Nilsson, P.; Vlachogianni, T.; Werner, S.; Galgani, F.; Thompson, R.C.; Dagevos, J.; Gago, J.; et al. Identifying Sources of Marine Litter; MSFD GES TG Marine Litter Thematic Report, EUR 28309; JRC: Ispra, Italy, 2016. [CrossRef]

14. Tornero, V.; Hanke, G. Potential Chemical Contaminants in the Marine Environment: An Overview of Main Contaminant Lists; EUR 28925; Publications Office of the European Union: Luxembourg, 2017; ISBN 978-92-79-77045-6. [CrossRef]

15. Palialexis, A.; Kousteni, V.; Boicenco, L.; Enserink, L.; Pagou, K.; Zweifel, U.L.; Somma, F.; Cheilari, A.; Connor, D. Monitoring biodiversity for the EU Marine Strategy Framework Directive: Lessons learnt from evaluating the official reports. Mar. Policy 2021, 128, 104473. [CrossRef]

16. Crise, A.; Kaberi, H.; Ruiz, J.; Zatsepin, A.; Arashkevich, E.; Giani, M.; Karageorgis, A.; Prieto, L.; Pantazi, M.; Fernandez, D.G.; et al. A MSFD complementary approach for the assessment of pressures, knowledge and data gaps in Southern European Seas: The PERSEUS experience. Mar. Pollut. Bull. 2015, 95, 28-39. [CrossRef]

17. Cinnirella, S.; Sardà, R.; de Vivero, J.L.S.; Brennan, R.; Barausse, A.; Icely, J.; Luisetti, T.; March, D.; Murciano, C.; Newton, A.; et al. Steps toward a shared governance response for achieving Good Environmental Status in the Mediterranean Sea. Ecol. Soc. 2014, 19, 47. [CrossRef]

18. Freire-Gibb, L.C.; Koss, R.; Margonski, P.; Papadopoulou, N. Governance strengths and weaknesses to implement the marine strategy framework directive in European waters. Mar. Policy 2014, 44, 172-178. [CrossRef]

19. Gelcich, S.; Buckley, P.; Pinnegar, J.K.; Chilvers, J.; Lorenzoni, I.; Terry, G.; Guerrero, M.; Castilla, J.C.; Valdebenito, A.; Duarte, C.M. Public awareness, concerns, and priorities about anthropogenic impacts on marine environments. Proc. Natl. Acad. Sci. USA 2014, 111, 15042-15047. [CrossRef] [PubMed]

20. Van Leeuwen, J.; van Hoof, L.; van Tatenhove, J. Institutional ambiguity in implementing the European Union Marine Strategy Framework Directive. Mar. Policy 2012, 36, 636-643. [CrossRef]

21. Murillas-Maza, A.; Uyarra, M.C.; Papadopoulou, K.N.; Smith, C.J.; Gorjanc, S.; Katja, K.; Klančnik, P.T.; Chalkiadakid, O.; Dassenakisd, M.; Pavicic, M. Programmes of measures of the marine strategy framework directive: Are they contributing to achieving good environmental status in the Mediterranean? Mar. Pol. Bull. 2020, 161, 111715. [CrossRef]

22. Cardoso, A.C.; Cochrane, S.; Doerner, H.; Ferreira, J.G.; Galgani, F.; Hagebro, C.; Hanke, G.; Hoepffner, N.; Keizer, P.D.; Law, R.; et al. Scientific Support to the European Commission Marine Strategy Framework Directive: Management Group Report, March 2010; European Commission, Joint Research Centre, International Council for the Exploration of the Sea (ICES): Luxembourg, 2010.

23. Eborja, A.; Elliott, M.; Andersen, J.H.; Eberg, T.; Ecarstensen, J.; Halpern, B.S.; Heiskanen, A.-S.; Ekorpinen, S.; Lowndes, J.S.S.; Emartin, G.; et al. Overview of Integrative Assessment of Marine Systems: The Ecosystem Approach in Practice. Front. Mar. Sci. 2016, 3. [CrossRef] 
24. Palialexis, A.; Connor, D.; Damalas, D.; Gonzalvo, J.; Micu, D.; Mitchel, I.; Korpinen, S.; Rees, A.F.; Somma, F. Indicators for Status Assessment of Species, Relevant to MSFD Biodiversity Descriptor; EUR 29820 EN; Publications Office of the European Union: Luxembourg, 2019; ISBN 978-92-76-09156-1. [CrossRef]

25. Hummel, H.; Frost, M.; Juanes, J.A.; Kochmann, J.; Bolde, C.F.C.P.; Aneiros, F.; Vandenbosch, F.; Franco, J.N.; Echavarri, B.; Xabier Guinda, X.; et al. A comparison of the degree of implementation of marine biodiversity indicators by European countries in relation to the Marine Strategy Framework Directive (MSFD). J. Mar. Biol. Assoc. UK 2015, 95, 1519-1531. [CrossRef]

26. EC. COM (2014) 97 Final (2014). Report from the Commission to the Council and the European Parliament. The First Phase of Implementation of the Marine Strategy Framework Directive (2008/56/EC); The European Commission's Assessment and Guidance: Brussels, Belgium, 2014.

27. Pendleton, L.H.; Beyer, H.; Estradivari, O.; Grose, S.; Hoegh-Guldberg, O.; Karcher, D.B.; Kennedy, E.; Llewellyn, L.; Nys, C.; Shapiro, A.; et al. Disrupting data sharing for a healthier ocean. ICES J. Mar. Sci. 2019, 76, 1415-1423. [CrossRef]

28. Lotze, H.K.; Guest, H.; O'Leary, J.; Tuda, A.; Wallace, D. Public perceptions of marine threats and protection from around the world. Ocean Coast. Manag. 2018, 152, 14-22. [CrossRef]

29. Piroddi, C.; Akoglu, E.; Andonegi, E.; Bentley, J.W.; Celić, I.; Coll, M.; Dimarchopoulou, D.; Friedland, R.; de Mutsert, K.; Girardin, R.; et al. Effects of nutrient management scenarios on marine food webs: A Pan-European Assessment in support of the Marine Strategy Framework Directive. Front. Mar. Sci. 2021, 8, 179. [CrossRef]

30. Hsieh, C.H.; Glaser, S.M.; Lucas, A.J.; Sugihara, G. Distinguishing random environmental fluctuations from ecological catastrophes for the North Pacific Ocean. Nature 2005, 435, 336-340. [CrossRef]

31. Maffucci, F.; Corrado, R.; Palatella, L.; Borra, M.; Marullo, S.; Hochscheid, S.; Lacorata, G.; Iudicone, D. Seasonal heterogeneity of ocean warming: A mortality sink for ectotherm colonizers. Sci. Rep. 2016, 6, 23983. [CrossRef]

32. Boyd, P.W.; Hutchins, D.A. Understanding the responses of ocean biota to a complex matrix of cumulative anthropogenic change. Mar. Ecol. Prog. Ser. 2012, 470, 125-135. [CrossRef]

33. Ottersen, G.; Planque, B.; Belgrano, A.; Post, E.; Reid, P.C.; Stenseth, N.C. Ecological effects of the North Atlantic Oscillation. Oecologia 2001, 128, 1-14. [CrossRef]

34. Myrberg, K.; Korpinen, S.; Uusitalo, L. Physical oceanography sets the scene for the Marine Strategy Framework Directive implementation in the Baltic Sea. Mar. Policy 2019, 107, 103591. [CrossRef]

35. Borja, A. Grand challenges in marine ecosystems ecology. Front. Mar. Sci. 2014, 1, 1. [CrossRef]

36. Tett, P.; Gowen, R.J.; Painting, S.J.; Elliott, M.; Forster, R.; Mills, D.K.; Bresnan, E.; Capuzzo, E.; Fernandes, T.F.; Foden, J.; et al. Framework for understanding marine ecosystem health. Mar. Ecol. Prog. Ser. 2013, 494, 1-27. [CrossRef]

37. Rossi, V.; Ser-Giacomi, E.; Lopez, C.; Hernández-García, E. Hydrodynamic provinces and oceanic connectivity from a transport network help designing marine reserves. Geophys. Res. Lett. 2014, 41, 2883-2891. [CrossRef]

38. Falcini, F.; Palatella, L.; Cuttitta, A.; Nardelli, B.B.; Lacorata, G.; Lanotte, A.S.; Santoleri, R. The role of hydrodynamic processes on anchovy eggs and larvae distribution in the Sicily Channel (Mediterranean Sea): A case study for the 2004 data set. PLoS ONE 2015, 10, e0123213. [CrossRef] [PubMed]

39. Solanki, H.U.; Prakash, P.; Dwivedi, R.M.; Nayak, S.; Kulkarni, A.; Somvamshi, V.S. Synergistic application of oceanographic variables from multi-satellite sensors for forecasting potential fishing zones: Methodology and validation results. Int. J. Remote Sens. 2010, 31, 775-789. [CrossRef]

40. Boon, P.J.; Clarke, S.A.; Copp, G.H. Alien species and the EU Water Framework Directive: A comparative assessment of European approaches. Biol. Invasions 2020, 22, 1497-1512. [CrossRef]

41. McEvoy, S.; Haasnoot, M.; Biesbroek, R. How are European countries planning for sea level rise? Ocean Coast. Manag. 2021, 203, 105512. [CrossRef]

42. IPCC. Climate Change 2014: Synthesis Report. Contribution of Working Groups I, II and III to the Fifth Assessment Report of the Intergovernmental Panel on Climate Change; Pachauri, R.K., Meyer, L.A., Eds.; IPCC: Geneva, Switzerland, $2014 ;$ p. 151.

43. Millennium Ecosystem Assessment. Ecosystems and Human Well-Being: Synthesis; Island Press: Washington, WA, USA, 2005.

44. Spash, C.L.; Ryan, A. Economic schools of thought on the environment: Investigating unity and division. Camb. J. Econ. 2012, 36, 1091-1121. [CrossRef]

45. Crise, A.; Ribera d'Alcalà, M.; Mariani, P.; Petihakis, G.; Robidart, J.; Iudicone, D.; Bachmayer, R.; Malfatti, F. A conceptual framework for developing the next generation of Marine Observatories (MOBs) for science and society. Front. Mar. Sci. 2018, 5, 318. [CrossRef]

46. Cavallo, M.; Elliott, M.; Touza, J.; Quintino, V. Benefits and impediments for the integrated and coordinated management of European seas. Mar. Policy 2017, 86, 206-213. [CrossRef]

47. Rossberg, A.G.; Uusitalo, L.; Berg, T.; Zaiko, A.; Chenuil, A.; Uyarra, M.C.; Borja, A.; Lynam, C.P. Quantitative criteria for choosing targets and indicators for sustainable use of ecosystems. Ecol. Indic. 2017, 72, 215-224. [CrossRef] [PubMed]

48. Juza, M.; Tintoré, J. Multivariate Sub-Regional Ocean Indicators in the Mediterranean Sea: From Event Detection to Climate Change Estimations. Front. Mar. Sci. 2021, 8. [CrossRef]

49. Boffetta, G.; Cencini, M.; Falcioni, M.; Vulpiani, A. Predictability: A way to characterize complexity. Phys. Rep. 2002, 356, 367-474. [CrossRef] 
50. Teixeira, H.; Berg, T.; Karin, F.; Uusitalo, L.; Papadopoulou, N.; Bizsel, K.C.; Cochrane, S.; Churilova, T.; Heiskanen, A.-S.; Uyarra, M.C.; et al. Existing Biodiversity, Non-Indigenous Species, Food-Web and Seafloor Integrity GES Indicators, DeliverableD3-1 of the DEVOTES Project. 2014. Available online: http:/ / www.devotes-project.eu/devotool (accessed on 26 July 2021).

51. Kersbergen, K.V.; Waarden, F.V. 'Governance' as a Bridge between Disciplines: Cross-disciplinary Inspiration Regarding Shifts in Governance and Problems of Governability, Accountability and Legitimacy. Eur. J. Political Res. 2004, 43, 143-171. [CrossRef]

52. Kooiman, J. Governing as Governance; Sage: London, UK, 2003.

53. Treib, O.; Bahr, H.; Falkner, G. Modes of Governance: A Note towards Conceptual Clarification. European Governance Papers (EUROGOV) N-05-02. 2005. Available online: https://www.researchgate.net/publication/331346038_Modes_of_Governance_A_ Note_Towards_Conceptual_Clarification_European_Governance_Papers_N-05-02_2005 (accessed on 26 July 2021).

54. Blatter, J. Forms of Political Governance: Theoretical Foundations and Ideal Types; Working Paper Series "Glocal Governance and Democracy" No.7; Department of Political Science, University of Lucerne: Lucerne, Switzerland, December 2012. Available online: https: / / ssrn.com/abstract=3008518 (accessed on 26 July 2021). [CrossRef]

55. Kenis, P.; Schneider, V. Policy Networks and Policy Analysis: Scrutinizing a New Analytical Toolbox. In Policy Networks. Empirical Evidence and Theoretical Considerations; Marin, B., Mayntz, R., Eds.; Campus Verlag: Frankfurt/Main, Germany, 1991 ; pp. $25-59$.

56. Héritier, A. New Modes of Governance in Europe: Governing in the Shadow of Hierarchy; Héritier, A., Rhodes, M., Eds.; Palgrave McMillan: New York, NY, USA, 2011; ISBN 978-0-230-30645-5.

57. Hollstein, B.; Matiaske, W.; Schnapp, K. Networked Governance; Springer: Berlin/Heidelberg, Germany, 2017; ISBN 978-3-31950386-8.

58. Schneider, V. Policy Networks and the Governance of Complex Societies. In Network of Culture; Kramer, S., Ed.; Springer: Berlin, Germany, 1944; pp. 27-44.

59. Eising, R.; Kohler-Koch, B. Introduction: Network Governance in the European Union. In The Transformation of Governance in the European Union; Kohler-Koch, B., Eising, R., Eds.; Routledge: London, UK, 1999.

60. Brafman, O.; Beckstrom, R.A. The Starfish and the Spider, the Unstoppable Power of Leaderless Organizations; Penguin: New York, NY, USA, 2006.

61. Bryhn, A.; Kaufvelin, P.; Bergstrom, U.; Vretborn, M.; Bergstrom, L. A Model for Disentangling Dependencies and Impacts among Human Activities and Marine Ecosystem Services. Environ. Manag. 2020, 65, 575-586. [CrossRef]

62. De Toni, A.F.; Biotto, G.; Battistella, C. Organizational design drivers to enable emergent creativity in web-based communities. Learn. Organ. 2012, 19, 335-349. [CrossRef]

63. De Toni, A.F.; Comello, L. Journey into Complexity; Marsilio Editori: Venice, Italy, 2007; ISBN 9781445260785.

64. Sereda, A.; Mikhaylichenko, Y.; Baklanov, P.; Kachur, A.; Lappo, A.; Danilova, L. Contribution of an Integrated Maritime Policy to the Dialogue of Civilisations: The Asia-Pacific Case. J. Mar. Sci. Eng. 2021, 9, 610. [CrossRef] 